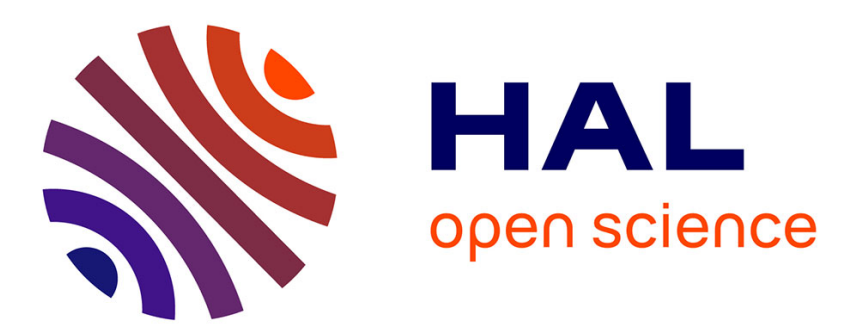

\title{
Photothermal reflectance microscopy : signal contrast in the case of thick and thin grain interfaces in solids
}

\author{
A. Mansanares, Z. Bozoki, T. Velinov, D. Fournier, A. Boccara
}

\section{To cite this version:}

A. Mansanares, Z. Bozoki, T. Velinov, D. Fournier, A. Boccara. Photothermal reflectance microscopy: signal contrast in the case of thick and thin grain interfaces in solids. Journal de Physique IV Proceedings, 1994, 04 (C7), pp.C7-575-C7-578. 10.1051/jp4:19947135 . jpa-00253190

\section{HAL Id: jpa-00253190 https://hal.science/jpa-00253190}

Submitted on 1 Jan 1994

HAL is a multi-disciplinary open access archive for the deposit and dissemination of scientific research documents, whether they are published or not. The documents may come from teaching and research institutions in France or abroad, or from public or private research centers.
L'archive ouverte pluridisciplinaire HAL, est destinée au dépôt et à la diffusion de documents scientifiques de niveau recherche, publiés ou non, émanant des établissements d'enseignement et de recherche français ou étrangers, des laboratoires publics ou privés. 


\title{
Photothermal reflectance microscopy: signal contrast in the case of thick and thin grain interfaces in solids
}

\author{
A.M. Mansanares*, Z. Bozoki**, T. Velinov***, D. Fournier and A.C. Boccara \\ Laboratoire d'Optique Physique, ESPCI, Laboratoire d'Instrumentation, UPMC, UPR A0005 du CNRS, \\ 10 rue Vauquelin, 75005 Paris, France \\ * Instituto de Física Gleb Wataghin, Universidade Estadual de Campinas, Unicamp, 13083-970 Campinas, \\ São Paulo, Brazil \\ ** Institute of Isotopes, The Hungarian Academy of Sciences, P.O. Box 77, 1525 Budapest, Hungary \\ *** Department of Solid State Physics, Sofia University, 5 blvd James Boucher, 1126 Sofia, Bulgaria
}

\begin{abstract}
In this work a thick interface model is proposed in order to describe the photothermal signal perturbation introduced by grain interfaces. The validity of the model is discussed based upon photothermal reflectance microscopy results obtained on Fe sintered samples. A comparison with the thermal resistance model, which is valid only in the case of thin interfaces, is also presented.
\end{abstract}

\section{INTRODUCTION}

In the last years several works dealing with interface influence in the heat diffusion processes in solids were presented [1-6]. The main interest of these works is related to the non-destructive control and to the characterization of the local properties of polycrystalline materials. In the first case the detection of defects such as subsurface crack by using photothermal techniques is at the origin of these studies. For the second case, the attention is mainly directed on the role of the grain boundaries and inter-grain phases in the heat diffusion. Knowing the exact shape and quantifying the signal perturbation when scanning across such interfaces is an important step in order to achieve standard analysis for these problems. Indeed we verify experimentally that the photothermal signal perturbation induced by interfaces in solids can present different shape, magnitude and phase shift from case to case. The origin of these differences remains on the actual nature of the interface (crack, grain-boundary, inter-grain layer, etc.).

In order to calculate the interface influence in the thermal diffusion problem, such interface has been frequently represented by a planar thermal resistance (thin interface). Such a model was considered in order to calculate the signal perturbation introduced by the thermal barrier when using the photothermal microscopy technique [1]. The comparison between calculation and experiments carried out on grain boundaries in $\mathrm{Fe}$ sintered samples shows that the thermal resistance model is applicable in some cases. There are, however, interfaces that exhibit strong thermal contrast that is not predictable by the thermal resistance model. In these cases we also observed a significant optical contrast (of the order of $10 \%$ ) at the boundary, indicating the presence of an interface layer. Thus, we propose here a thick interface model, which takes into account the thermal properties of the layer. As we show below, the calculation fits our experimental results when the thickness of the layer is not negligible compared to the pump and to the probe beam radius, and when its thermal properties (thermal conductivity and diffusivity) are much smaller than the grain ones.

\section{EXPERIMENTAL}

The experimental results were obtained by using a photothermal reflectance microscope [1]. An 
intensity modulated $\mathrm{Ar}^{+}$laser beam $(514.5 \mathrm{~nm}, 3-$ $10 \mathrm{~mW}$ on the sample) is used as excitation, and a continuous diode laser beam $(670 \mathrm{~nm}, 0.25 \mathrm{~mW}$ on the sample) probes the induced sample reflectance variation. Both the excitation and the probe spot size on the sample are about $1.0 \mu \mathrm{m}$ diameter. In order to scan the sample surface, a $0.1 \mu \mathrm{m}$ stepsize translation stage is used. Modulation frequencies of $0.1-12 \mathrm{MHz}$ were employed.

In Fig. 1 we show the photothermal signal when scanning across a grain interface in a $\mathrm{Fe}$ sintered sample. Sample preparation is described elsewhere [1]. The modulation frequency was $1.03 \mathrm{MHz}$. An optical contrast (not shown) of about $10 \%$ was observed at pump and probe wavelength. No normalization by the absorption and reflection flux was performed, since these effects (estimated using the measured sample reflectance at pump wavelength, $R_{\text {pump }}=0.5$ ) negligible compared to the total perturbation observed at the grain interface. We can observe that the amplitude contrast, defined as the perturbation divided by the homogeneous sample signal (signal far from the interface), is $100 \%$ and the phase shift is $8^{\circ}$. As we discuss below, for the thermal resistance model, the maximum amplitude contrast is roughly $25 \%$, and the maximum phase shift is $4^{0}$. So, this model fails in describing the grain interface of Fig. I. Furthermore, the frequency dependence of the amplitude contrast and phase shift for this interface, shown in Fig. 2, can not be described by the thermal resistance model. In this model, the amplitude contrast always decreases with modulation frequency, while the experimental results show an increasing behavior for this quantity.

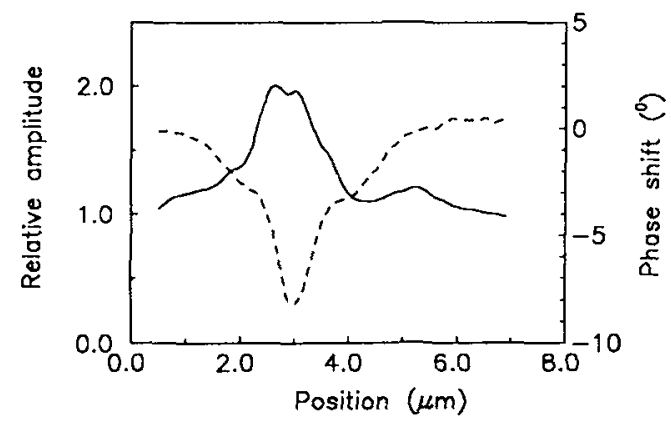

liggure I: Experimemal curves for amplinude (solid line) and phase (dashed line) of the photothermal signal alomg a line perpendicular to a grain interface in Fe simtered sample. Modulation frequency was $1.03 \mathrm{MHz}$.

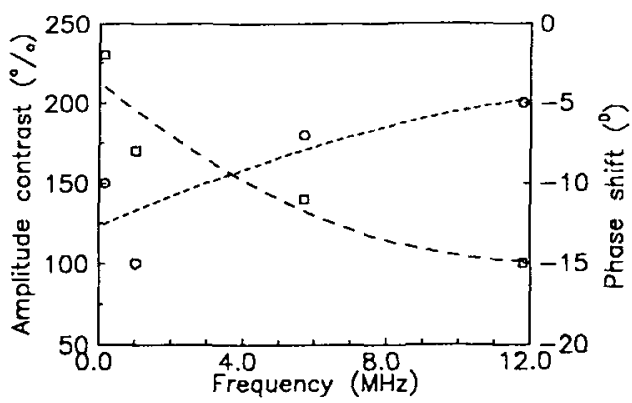

Figure 2: lixperimental values for the amplitude contrast (circles) and the phase shifi (squares), for the grain interface of Fig. 1 , as a function of the modulation frequency.

\section{THIN AND THICK INTERFACE MODELS}

\subsection{Thin interface model}

Representing the interface by a planar thermal resistance, and considering it perpendicular to the sample surface (vertical thermal barrier), we can find analytical expressions for the photothermal reflectance signal. A detailed discussion is found in Ref. 1 . The main feature of the signal in this case is a double-hump curve for amplitude and phase (inverted), symmetrical with respect to the interface. The amplitude contrast and phase shift depend on the thermal resistance $R_{T}$, and saturate (become independent of $R_{T}$ ) for modulation frequencies such that the thermal diffusion length $\mu_{\mathrm{S}}$ is much smaller than the product $\mathrm{R}_{\mathrm{T}} \mathrm{k}_{\mathrm{S}}\left(\mathrm{k}_{\mathrm{S}}\right.$ is the sample thermal conductivity). In the saturated case, the amplitude contrast and phase shift introduced by the thermal barrier are maximum, and we can find an analytical expression for the signal as a function of the modulation frequency. Indeed, in this situation, the signal becomes independent of the spatial scale, and is a function only of the ratio $\left(R_{0} / \mu_{s}\right), R_{0}$ being the pump beam radius. Figure 3 shows the amplitude contrast and the phase shift for the saturated case, as a function of $\left(\mathrm{R}_{0} / \mu_{\mathrm{s}}\right)$. As mentioned above, we see that the maximum amplitude contrast is about $25 \%$, and occurs at low modulation frequency, while the maximum phase shift is about $4^{(0)}$ and occurs for modulation frequencies such that the thermal diffusion length is of the order of the pump beam radius. 


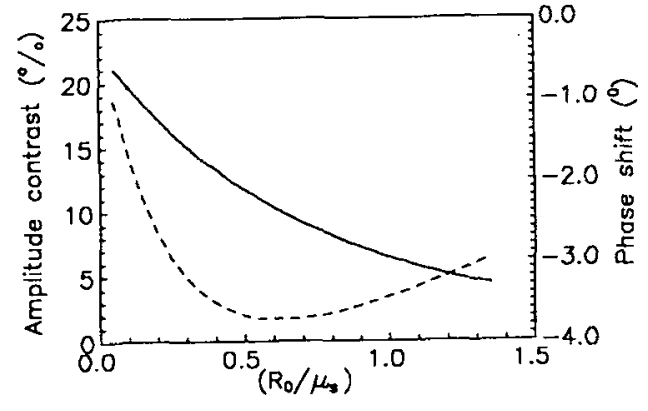

Figure 3: Calculated amplitude contrast (solid lime) and phase shifi (dashed line) for the vertical thermal resistance, in the saturated limit $\left(\mu_{\mathrm{s}}<<R_{\mathrm{T}} \mathrm{k}_{\mathrm{s}}\right)$, as a function of $\left(R_{0} \mu_{\mathcal{S}}\right)$.

\subsection{Thick interface model}

In this case we consider an interface layer with thermal properties different from the grain ones. The thermal conductivity and diffusivity were taken as being smaller for the layer than for the Fe grains. The layer was considered perpendicular to the sample surface, and finite-element algorithm was used. For layer thickness much smaller than the pump and the probe beam radius, the obtained results are similar to those of the thermal resistance model $\left(R_{T}\right.$ being replaced by layer thickness $\left./ k_{\text {layer }}\right)$. However, when the layer thickness is not negligible compared to the pump beam radius, for appropriated values of the thermal properties of the interface layer, we got signal shape, amplitude contrast and phase shift, that point in the direction of the experimental results. For instance, Fig. 4 shows the relative amplitude and the phase shift for the temperature when scanning across a thick interface. The layer thickness and the thermal properties are indicated in the figure caption. We can see the single peak shape of the perturbation and its stronger amplitude contrast and phase shift compared to the thermal resistance results.

In order to find the frequency dependence of the amplitude contrast and phase shift, we calculated the temperature at the center of the interface layer, on the sample surface. Figure 5 shows that the amplitude contrast increases with modulation frequency, in opposition to the thermal resistance model, and in agreement with our experimental results. In the same way, the absolute values of the phase shift also increase with modulation frequency, and is of the same order of the measured values.

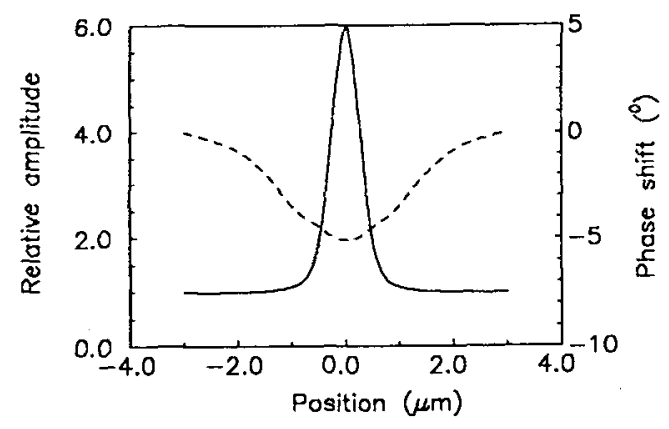

Figure 4: Calculated temperature amplitude (solid line) and phase shift (dashed line) when scaming a thick imerface. The layer thickness was $0 . t \mu \mathrm{m}$ and the pump and probe beam radii were $0.5 \mu \mathrm{m}$. $k_{\text {grain }} / k_{\text {laver }}=\alpha_{\text {grain }} / \alpha_{\text {laver }}=50$, and $\alpha_{\text {grain }}=0.12$ $\mathrm{cm}^{2} / \mathrm{s}$. Modulation frequency was $1.0 \mathrm{MHz}$.

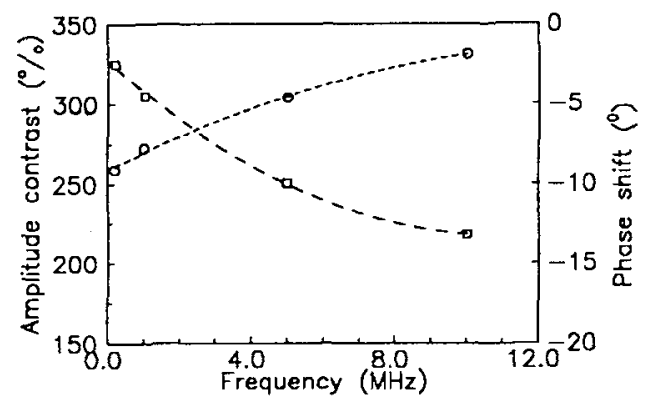

Figure 5: Calculated values for the amplitude contrast (circles) and the phase shifi (squares) of the temperature for a thick interface, as a function of the modulation frequercy: The pump beam radius was $0.5 \mu \mathrm{m}$ and the interface thickness was $0.2 \mu \mathrm{m}$. The interface was considered to have the air thermal properties. 
In conclusion, we showed that a thick interface model, which takes into account the thermal properties of an interface layer with thickness of the order of the pump and the probe beam radius, is useful in describing the signal perturbation introduced by the interface when using photothermal reflectance microscopy. We observed that the simple thermal resistance model is applicable only for the cases of thin interfaces. Analyzing the experimental results obtained when scanning grain boundaries, we note several distinct signal shapes, which are related to the nature and orientation of the interface. Up to now we have treated the thin (vertical and slanted, see Ref. 1) and the thick interface cases. Open cracks and optical modulation by knife edge-like effects engendered by the interface must be considered in further investigations.

A.M.M. is grateful to the Brazilian Agencies CNPq and FAPESP.

\section{REFERENCES}

[1] Mansanares A. M., Velinov T., Bozoki Z., Fournier D. and Boccara A. C., J. Appl. Phys. 75 (1994) 3344-3350.

[2] Guitonny J., Bozoki Z., Mansanares A. M., Le Liboux M., Fournier D. and Boccara A. C., Optics Comm. 104 (1993) 61-64.

[3] McDonald F. A., Wetsel Jr. G. C. and Jamieson G. E., Can. J. Phys. 64 (1986) 12651268.

[4] Grice K. R., Inglehart L. J., Favro L. D., Kuo P. K. and Thomas R. L., J. Appl. Phys. 54 (1983) 6245-6255.

[5] Lepoutre F., Fournier D. and Boccara A. C., "Macro-, Meso- and Microscopic Heat Diffusion in Ceramics", Photoacoustic and Photothermal Phenomena III (Springer-Verlag, 1992) pp. 717-720.

[6] Meyer-Berg G., Osiander R., Korpium P., Kakoschke P. and Joswig $H_{\text {., "The Thermal }}$ Resistance of Grain Boundaries Determined by Modulated Optical Reflectance", Photoacoustic and Photothermal Phenomena III (Springer-Verlag, 1992) pp. 711-713. 